\title{
Miniaturized biosignature analysis reveals implications for the formation of cold seep carbonates at Hydrate Ridge (off Oregon, USA)
}

\author{
T. Leefmann ${ }^{1}$, J. Bauermeister ${ }^{1}$, A. Kronz ${ }^{1}$, V. Liebetrau ${ }^{2}$, J. Reitner ${ }^{1}$, and V. Thiel ${ }^{1}$ \\ ${ }^{1}$ Geoscience Centre (GZG), University of Göttingen, Göttingen, Germany \\ ${ }^{2}$ Leibniz-Institut für Meereswissenschaften (IfM-GEOMAR), Kiel, Germany \\ Received: 9 November 2007 - Published in Biogeosciences Discuss.: 28 November 2007 \\ Revised: 7 April 2008 - Accepted: 7 April 2008 - Published: 7 May 2008
}

\begin{abstract}
Methane-related carbonates from Hydrate Ridge typically show several macroscopically distinguishable mineral phases, namely whitish aragonite, lucent aragonite, and gray micrite. The relationship of these phases to particular microorganisms or biogeochemical processes is as yet unclear. We used a miniaturized biomarker technique on mg samples, combined with factor analysis and subsequent electron microprobe analysis, to study lipid biomarkers and chemical compositions of the individual phases. This allows us to identify particular mechanisms involved in the formation of the different carbonate precipitates. Our combined analysis of biomarkers and petrographic traits shows that most of the lipids related to the anaerobic oxidation of methane ( $>90 \%$ by weight) are concentrated within only a minor compartment ( $\sim 20 \%$ by volume) of the Hydrate Ridge carbonates, the whitish aragonite. The patterns indicate that the whitish aragonite represents fossilized biofilms of methanotrophic consortia containing mainly archaea of the ANME-2 group and sulfate reducing bacteria, whereas the precipitation of the lucent aragonite may have lacked the immediate proximity of microorganisms during formation. By contrast, the gray micrite formed by incorporation of allochthonous organic and inorganic matter during carbonate precipitation induced by the anaerobic oxidation of methane involving ANME-1 archaea.
\end{abstract}

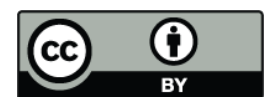

Correspondence to: V. Thiel (vthiel@gwdg.de)

\section{Introduction}

Specific carbonates occur at cold seep sites, where methanerich fluids are exiting the seafloor. These "seep carbonates" typically show highly negative $\delta^{13} \mathrm{C}$ values (Greinert et al., 2001 ), indicating that they formed from bicarbonate produced by the anaerobic oxidation of methane (AOM; Ritger et al., 1987) according to the overall reaction:

$\mathrm{CH}_{4}+\mathrm{SO}_{4}^{2-} \rightarrow \mathrm{HCO}_{3}^{-}+\mathrm{HS}^{-}+\mathrm{H}_{2} \mathrm{O}$

The production of bicarbonate leads to an increase in alkalinity and thus to the precipitation of authigenic carbonates. These carbonates can grow within the sediment (Bohrmann et al., 1998; Greinert et al., 2001) or they may form build-ups growing into the anoxic (Michaelis et al., 2002, Reitner et al., 2005) or oxic (Teichert et al., 2005) water column. Seep carbonates commonly display distinct phases (Peckmann et al., 2001) which are thought to derive from varying influence of microorganism, pelagic rain from the water column, and fluid seepage fueling the AOM activity (Teichert et al., 2005). AOM is mediated by a consortium of methanotrophic archaea and sulfate-reducing bacteria (SRB), which have been characterized by $16 \mathrm{~S}$ rRNA investigations (Hinrichs et al., 1999; Boetius et al., 2000). Two major phylogenetic groups of methanotrophic archaea (ANME-1 and ANME2, ANME=anaerobic $m e$ thane oxidizers) were distinguished. While ANME-2 archaea have been observed in tight association with SRB of the Desulfosarcina/Desulfococcus group, ANME-1 archaea sometimes occur with these SRB, but in other cases are observed as monospecific aggregations or isolated filaments (Orphan et al., 2002). In anoxic marine sediments, carbonate crusts, and recent microbial mats from cold seep sites, methanotrophic consortia can be traced using specific, strongly ${ }^{13} \mathrm{C}$-depleted biomarkers. Different

Published by Copernicus Publications on behalf of the European Geosciences Union. 
species of methanotrophic archaea are considered to be the sources of characteristic isoprenoids (Hinrichs et al., 1999; Blumenberg et al., 2004; Elvert et al, 2005; Pape et al., 2005). These isoprenoids include $\mathrm{C}_{20}$ and $\mathrm{C}_{25}$ irregular isoprenoid hydrocarbons (2,6,11,15-tetramethylhexadecane (crocetane) and 2,6,10,15,19-pentamethylicosane (PMI) and unsaturated derivatives), the glycerol diethers archaeol and $s n$-2-hydroxyarchaeol (2,3-di- $O$-phytanyl-sn-glycerol and 2$O$-3-hydroxyphytanyl-3- $O$-phytanyl-sn-glycerol), as well as glycerol dialkyl glycerol tetraethers (GDGT) carrying two $\mathrm{C}_{40}$ isopranyl moieties.Non-isoprenoid monoalkylglycerolethers (MAGEs), 1,2-dialkylglycerolethers (DAGEs), and $\mathrm{C}_{14}$ to $\mathrm{C}_{18} n$-, iso-, and anteiso-fatty acids, as well as alcohols found at cold seeps have commonly been regarded as biomarkers for associated SRB (Hinrichs et al., 2000; Pancost et al., 2001).

The cold seep sites at Hydrate Ridge, located about 90 $\mathrm{km}$ off the coast of Oregon (USA) at $600 \mathrm{~m}$ to $800 \mathrm{~m}$ water depth, have been extensively studied since the mid-1980s. Different seep carbonate lithologies have been the targets of several investigations (Ritger et al., 1987; Kulm and Suess, 1990; Bohrmann et al., 1998; Greinert et al., 2001). Generally, authigenic chemoherm carbonates from Hydrate Ridge consist primarily of aragonite (Greinert et al., 2001). At South East-Knoll (SE-Knoll), an up to $90 \mathrm{~m}$ elevated chemoherm located about $15 \mathrm{~km}$ south-east of the southern summit of Hydrate Ridge (Bohrmann et al., 2000), three major carbonate types are closely interfingered. These types consist of (i) a macroscopically opaque, cryptocrystalline variety of aragonites ranging in color from white to pinkish and brownish, (ii) a translucent aragonite consisting of fibrous, acicular crystals, and (iii) a gray, microcrystalline carbonate with varying content of $\mathrm{Mg}$-calcite and various components, namely shell fragments, pellets containing pyrite, peloids and detrital quartz, and feldspar grains (Teichert et al., 2005).

In order to study the linkage of these phases to particular microorganisms and/or biogeochemical processes, we used a miniaturized biomarker technique, combined with factor analysis, and subsequent electron microprobe and stable isotope analyses. The aim was to identify differences in the lipid biomarker patterns and the chemical compositions between the phases that would allow us to understand the mechanisms involved in the formation of the particular carbonate precipitates.

\section{Material and methods}

\subsection{Sample collection}

The samples were obtained from a carbonate block collected during cruise SO165/2 of RV "Sonne" in August 2002. The block was gathered directly from the top of the SEKnoll chemoherm using a television grab (TVG; Station 2301, TVG-13, 44:27.0440 ${ }^{\circ} \mathrm{N}, 125: 01.8000^{\circ} \mathrm{W}, 615 \mathrm{~m}$ water depth). First U-Th isotope analyses of 5 sub-samples from a drill core out of the carbonate block using the multi-collector inductively-coupled plasma mass spectrometry (MC-ICPMS) method after Fietzke et al. (2005) imply distinct precipitation phases of cold seep related carbonates between 205 and $98 \mathrm{ka} \mathrm{BP}$ (unpublished). Based on the classification of Teichert et al. (2005), the drill core consists of $\sim 20$ vol.- $\%$ "whitish aragonite", $\sim 40$ vol.-\% "lucent aragonite", and $\sim 40$ vol.-\% "gray micrite".

\subsection{Sample preparation}

From the $28.5 \mathrm{~cm}$ (length) by $50 \mathrm{~mm}$ (diameter) core drilled out of sample TVG-13, 18 micro-drill cores $(<2 \mathrm{~mm}$ long, $2 \mathrm{~mm}$ in diameter, $6-21 \mathrm{mg}$ in weight) were predrilled using a diamond-studded hollow drill and removed/retrieved using a small chisel and a tweezers. Microscope observations allowed classification of the micro-drill cores and assignment to the three distinct phases: (i) "whitish aragonite" (8 samples), (ii) "lucent aragonite" (6 samples), and (iii) "gray micrite" (4 samples). The samples were transferred into glass vials, ground to powder with a small pestle, and extracted using $200 \mu \mathrm{L} \mathrm{CH}_{2} \mathrm{Cl}_{2}$ and ultrasonication (35 min; $\left.60^{\circ} \mathrm{C}\right)$. The supernatant was decanted after centrifuging. The extraction process was repeated twice. The combined extracts were dried and derivatized by adding $50 \mu \mathrm{L}$ N,O-bis(trimethylsilyl)trifluoroacetamide (BSTFA; $90 \mathrm{~min}$; $80^{\circ} \mathrm{C}$ ). The reaction mixtures were dried in a gentle stream of nitrogen and redissolved in $n$-hexane. $2 \mu \mathrm{L}$ of $n$-hexane were added for each $\mathrm{mg}$ of the weighted carbonate sample. $1 \mu \mathrm{L}$ of each extract was analyzed in a coupled gas chromatograph mass spectrometer (GC/MS). Extracts of sample $7 \mathrm{r} 1$ and $9 \mathrm{a}$ were dried and transesterified by adding $200 \mu \mathrm{L}$ trimethylchlorosilane/methanol (TMCS/MeOH, 1:10, v/v; $60 \mathrm{~min}, 70^{\circ} \mathrm{C}$ ). The resulting fatty acid methyl ester derivatives were re-dissolved in $200 \mu \mathrm{L} n$-hexane and analyzed by GC/MS.

The main advantage of the presented micro-sampling technique is the achievement of a better resolution on biomarker distribution within a sample. This allows analyzing the surrounding matter with chemical imaging techniques such as electron microprobe, which may help to link the organic and inorganic chemical features of a given sample on a small scale. When preparing and analyzing such small sample amounts, however, particular care has to be taken in order to avoid contamination with laboratory contaminants that may obscure target compounds and complicate compound identification and quantification.

\section{$2.3 \mathrm{GC} / \mathrm{MS}$}

The GC/MS system used was a Varian CP-3800 GC coupled to a Varian 1200 quadrupole MS operated in electron impact mode at $70 \mathrm{eV}$. The samples were injected on-column into a fused silica capillary column (Phenomenex ZB-1; $30 \mathrm{~m}$; 
$0.25 \mathrm{~mm} ; 0.1 \mu \mathrm{m}$ film thickness). In the injector, the samples were heated from $50^{\circ} \mathrm{C}(0.2 \mathrm{~min}$ isothermal $)$ to $290^{\circ} \mathrm{C}$ at $150^{\circ} \mathrm{C} / \mathrm{min}$ (5 min isothermal). The $\mathrm{GC}$-oven was programed from $50^{\circ} \mathrm{C}\left(1 \mathrm{~min}\right.$ isothermal) to $300^{\circ} \mathrm{C}$ at $10^{\circ} \mathrm{C} / \mathrm{min}$, and was held at $300^{\circ} \mathrm{C}$ for $15 \mathrm{~min}$. Helium was used as the carrier gas at a flow rate of $1.4 \mathrm{~mL} / \mathrm{min}$. Compounds were identified by comparison with published mass spectral data.

\subsection{Factor analysis}

A factor analysis was implemented using Statistica 6.0, developed by Statsoft Inc. Tulsa. The compound concentrations were treated as multivariate to show correlations of the compounds with each other (biomarker families). Absolute concentrations (in $\mu \mathrm{g} / \mathrm{g}$ carbonate weighted samples) were used as base data. Factors were extracted by Principle Component Analyses (PCA). The maximum number of factors to be extracted was determined using the scree test (Cattel, 1966). The rotational strategy was varimax normalized (Kaiser, 1958, 1959).

\subsection{Stable istopes}

11 samples of carbonates were taken in the direct vicinity of selected micro-drill cores used for biomarker analyses. Stable oxygen and carbon isotope measurements of these samples were carried out at the isotope laboratory at IfMGEOMAR (Kiel, Germany) with a CARBO KIEL automated carbonate preparation device linked on-line to a FINNIGAN MAT 252 mass spectrometer. External reproducibility was $0.03 \%$ for $\delta^{13} \mathrm{C}$ and $0.02 \%$ for $\delta^{18} \mathrm{O}$ (1-sigma values), as calculated from 8 replicate analyses of the internal carbonate standard (Solnhofen Limestone) performed before and after the analyses of our carbonate samples. The isotope data are referred to the Pee Dee Belemnite (PDB) scale.

\subsection{Electron microprobe analysis}

Polished thin sections $(250 \mu \mathrm{m}$ thickness $)$ were prepared from sampled areas of the carbonate. Element distributions of $\mathrm{Mg}, \mathrm{S}, \mathrm{Mn}, \mathrm{Fe}, \mathrm{Sr}$ (wavelength dispersive system), and $\mathrm{Ca}$ (energy dispersive system) were mapped using a JEOL JXA 8900 RL electron microprobe. The acceleration voltage was set to $15 \mathrm{kV}$ and a beam current of $40 \mathrm{nA}$, measured by Faraday cup, was used. The acquisition time was set to $70 \mathrm{~ms}$ per step. The scan grid was spaced at 20 or $40 \mu \mathrm{m}$ steps, depending on the dimension of each area, resulting in total dimensions between $7 \times 5$ and $10 \times 20 \mathrm{~mm}$. The backscatter signal in composition mode and the cathodoluminescence signal (integrated spectral range from 200 to $900 \mathrm{~nm}$ ) were acquired simultaneously. Since carbonates have sensitive behavior under electron bombardment, the beam diameter was set to $20 \mu \mathrm{m}$.

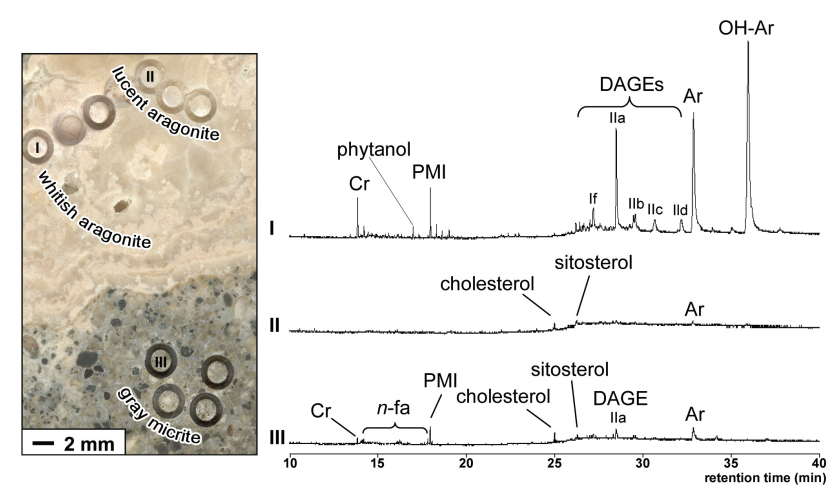

Fig. 1. Enlarged image of area 3 (see Fig. 3) sampled for lipid biomarker analyses (left) and total ion currents (right) of individual micro-drill cores. (I) whitish aragonite (sample $7 \mathrm{r} 1$ ); (II) lucent aragonite (sample 8c); (III) gray micrite (sample 10r3). $\quad(\mathrm{Cr}=$ crocetane $\quad(2,6,11,15$-tetramethylhexadecane $)$, $\mathrm{PMI}=2,6,10,15,19$-pentamethylicosane, $\mathrm{Ar}=$ archaeol $\quad(2,3-$ di- $O$-phytanyl-sn-glycerol), $\quad \mathrm{OH}-\mathrm{Ar}=s n$-2-hydroxyarchaeol (2-O-3-hydroxyphytanyl-3- $O$-phytanyl-sn-glycerol), DAGE If $=1,2$-di- $O-12$-methyltetradecyl-sn-glycerol, DAGE IIa=1-Otetradecyl-2- $O$-11,12-methylenehexadecyl-sn-glycerol, DAGE $\mathrm{IIb}=1-O$-pentadecyl-2- $O$-11,12-methylenehexadecyl-sn-glycerol, DAGE IIc=1- $O$-hexadecyl-2- $O-11,12-$ methylenehexadecyl-snglycerol, DAGE IId=1-O-11-cyclohexylundecyl-2- $O$-11,12methylenehexadecyl-sn-glycerol (abbreviations according to Pancost et al., 2001a), phytanol=3,7,11,15-tetramethylhexadecane1 -ol, cholesterol=cholest-5-en $-3 \beta$-ol, sitosterol=24-ethylcholest-5$e n-3 \beta$-ol, $n$-fa $=n$-fatty acids).

\section{Results}

\subsection{Biomarkers}

The whitish aragonite samples showed the highest lipid biomarker concentrations, containing more than $90 \%$ of the total AOM-related lipid signature observed (Table 1, Fig. 1). In all whitish aragonite samples $(n=8)$, archaeol, $s n$-2-hydroxyarchaeol, and DAGEs were the most prominent lipid biomarkers (Table 1). In 5 out of 8 samples, $s n$ 2-hydroxyarchaeol was more abundant than archaeol. The most abundant DAGE showed $n$ - $\mathrm{C}_{14}$ and $\mathrm{C}_{17}$-cyclopropyl moieties at the $s n-1$ and $s n-2$ positions, respectively (DAGE IIa according to the designation given by Pancost et al., 2001a). Another, somewhat less abundant, DAGE containing two anteiso- $\mathrm{C}_{15}$ alkyl chains was observed in the whitish aragonite samples (DAGE If according to Pancost et al., 2001a). Other DAGEs occurred in trace concentrations. Furthermore, crocetane, PMI, and phytanol occurred in all whitish aragonite samples, but with concentrations of about an order of magnitude lower than those of the ether lipids (Table 1). Low amounts of $n$ - $\mathrm{C}_{14}$ to $n$ - $\mathrm{C}_{18}$ fatty acids were present in all whitish aragonite samples, whereas terminally branched fatty acids were not detected. 
Table 1. Concentrations of lipid biomarkers ( $\mu \mathrm{g} / \mathrm{g}$ of rock; crocetane=2,6,11,15-tetramethylhexadecane, PMI=2,6,10,15,19pentamethylicosane, phytanol=3,7,11,15-tetramethylhexadecane-1-ol, archaeol=2,3-di- $O$-phytanyl-sn-glycerol, $s n$-2-hydroxyarchaeol=2$O$-3-hydroxyphytanyl-3- $O$-phytanyl-sn-glycerol, DAGE If=1,2-di- $O$-12-methyltetradecyl-sn-glycerol, DAGE IIa=1- $O$-tetradecyl-2- $O$ 11,12-methylenehexadecyl-sn-glycerol, $n$ - $\mathrm{C}_{X}=$ saturated $n$-alkane containing $X$ carbon atoms, cholesterol=cholest-5-en-3 $\beta$-ol, sitosterol $=24, n-\mathrm{C}_{X}$ fa=saturated $n$-fatty acid containing $X$ carbon atoms, n.d.=not detected) and stable isotopes (PDB=Pee Dee Belemnite; n.a. $=$ not analyzed). ${ }^{*}=$ samples for $\delta^{13} \mathrm{C}$ and $\delta^{18} \mathrm{O}$ analyses of carbonates were taken in the direct vicinity of the respective micro-drill cores used for biomarker analyses.

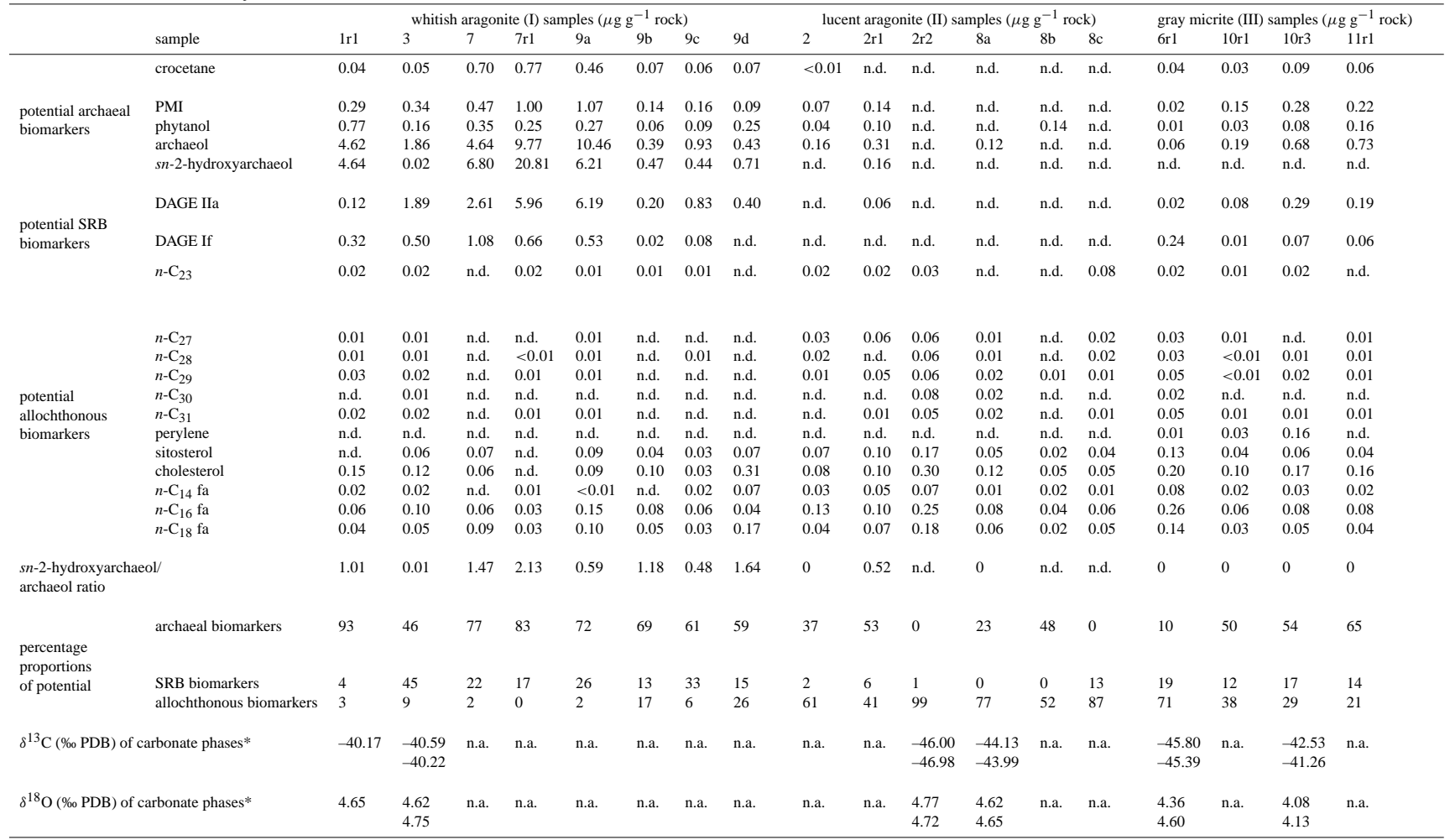

Unlike the whitish aragonite, the lucent aragonite samples $(n=6)$ contained only trace amounts of lipid biomarkers (Table 1$)$. $n$-Alkanes ( $n-\mathrm{C}_{23}$ to $\left.n-\mathrm{C}_{31}\right), n$-fatty acids ( $n-\mathrm{C}_{14}$ to $n$ $\mathrm{C}_{18}$ ), squalene, and sterols, specifically cholesterol and sitosterol, dominate the patterns. In 2 out of 6 samples, PMI was detected, whereas phytanol and $s n$-2-hydroxyarchaeol were observed in only one sample each. Archaeol was found in three samples, while crocetane and DAGEs were generally below the detection limit in the lucent aragonite (Table 1).

The gray micrite samples $(n=4)$ were characterized by archaeol as the main compound, although its absolute concentrations were on average one order of magnitude lower than in the whitish aragonite (Table 1). Notably, sn-2hydroxyarchaeol was completely absent from the gray micrite, whereas smaller amounts of DAGEs, PMI, crocetane, sterols, $n$-fatty acids, and trace amounts of $n$-alkanes were evident. Average concentrations of sterols and $n$-fatty acids were even higher in the gray micrite than in the whitish aragonite, except for $n-\mathrm{C}_{18}$, which was similarly abundant in both phases. A specific trait of the gray micrite was the occurrence of perylene, which was found in 3 of the 4 samples analyzed.

\subsection{Factor analysis}

The two factors extracted accounted for $44.9 \%$ and $24.6 \%$ of the total variance. The factor loadings plot revealed a compound group consisting of PMI, crocetane, DAGE IIa, DAGE If, archaeol, sn-2-hydroxyarchaeol, and phytanol, which has slightly negative loadings with factor 1 and highly positive loadings with factor 2 (Fig. 2). A second group of compounds that loads positive with factor 1 and slightly negative with factor 2 included $n$-alkanes, $n$-fatty acids, and sterols. One compound, $n$-tricosane $\left(n-\mathrm{C}_{23}\right)$, plotted between the two compound groups.

\subsection{Stable isotopes}

The stable $\delta^{13} \mathrm{C}$-values of the whitish aragonite samples range from -40.17 to $-40.59 \%$ o $\mathrm{PDB}$, whereas $\delta^{18} \mathrm{O}$-values varied between $4.65 \%$ PDB and $4.75 \%$ PDB (Table 1). Slightly lower $\delta^{13} \mathrm{C}$-values were measured for the lucent aragonite samples $(-43.99$ to $-46.98 \%$ o PDB). The $\delta$-values measured for stable oxygen isotopes range from 4.62 to $4.77 \%$ PDB. The gray micrite samples had an intermittent 


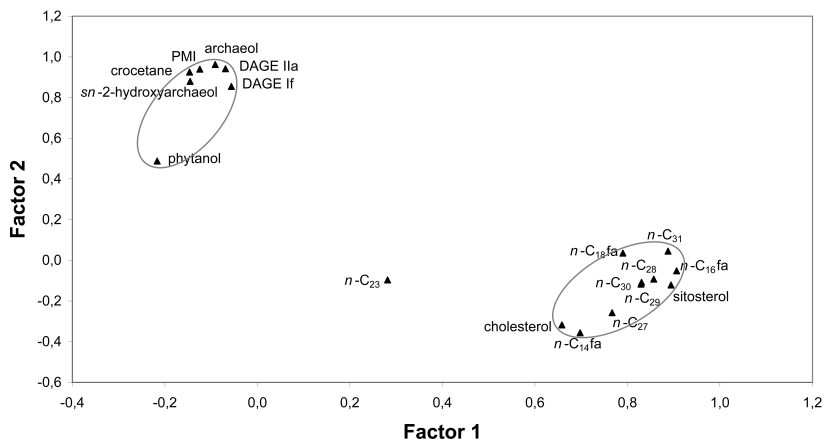

Fig. 2. Two-dimensional plot of compound factor loadings showing two distinct groups of lipid biomarkers (marked by gray ellipses) ( $n-\mathrm{C}_{X}=$ saturated $n$-alkane containing $X$ carbon atoms, $\quad \mathrm{Cr}=$ crocetane $(2,6,11,15$-tetramethylhexadecane), $\mathrm{PMI}=2,6,10,15,19$-pentamethylicosane, $\mathrm{Ar}=$ archaeol (2,3-di- $O$ phytanyl-sn-glycerol), $\mathrm{OH}-\mathrm{Ar}=s n$-2-hydroxyarchaeol $\quad(2-O-3-$ hydroxyphytanyl-3- $O$-phytanyl-sn-glycerol), DAGE If=1,2-di- $O$ 12-methyltetradecyl-sn-glycerol, DAGE IIa=1- $O$-tetradecyl-2- $O$ 11,12-methylenehexadecyl-sn-glycerol, (abbreviations according to Pancost et al., 2001a); phytanol=3,7,11,15-tetramethylhexadecane1-ol; cholesterol=cholest-5-en-3 $\beta$-ol; sitosterol=24-ethylcholest-5$e n-3 \beta$-ol; $n-\mathrm{C}_{X}$ fa $=n$-fatty acid containing $X$ carbon atoms).

stable carbon isotope signature ( -41.26 to $-45.80 \%$ PDB), whereas the $\delta^{18} \mathrm{O}$-values ( 4.08 to $4.60 \%$ o $\mathrm{PDB}$ ) were slightly lower than those of the aragonites.

\subsection{Electron microprobe analyses}

The electron microprobe data showed that the whitish aragonite was considerably enriched in $\mathrm{Sr}$ compared to the lucent aragonite (Fig. 3h). Both aragonite phases nevertheless revealed higher $\mathrm{Sr}$ concentrations than the gray micrite (Fig. 3f). The Ca-signal was somewhat enhanced in the lucent aragonite compared to the whitish aragonite and the gray micrite (Fig. 3e). Mn was not observed in any of the phases. $\mathrm{Fe}, \mathrm{Mg}$, and $\mathrm{S}$ were detected in the gray micrite, but they were below detection limit in the aragonites. In the gray micrite, distributions of $\mathrm{Mg}$ and $\mathrm{Ca}$ were anticorrelating (Fig. 3c, e), S and Fe, on the other hand, spatially correlated (Fig. 3b, d).

\section{Discussion}

\subsection{Whitish aragonite}

As indicated by factor analyses (Fig. 2) the strong correlation between the concentrations of PMI, crocetane, DAGE IIa, DAGE If, archaeol, and $s n$-2-hydroxyarchaeol suggests that these AOM-related biomarkers originate from a closely associated biological source. Blumenberg et al. (2004) proposed high proportions of $s n$-2-hydroxyarchaeol vs. archaeol and the presence of crocetane, as traits to distinguish micro-

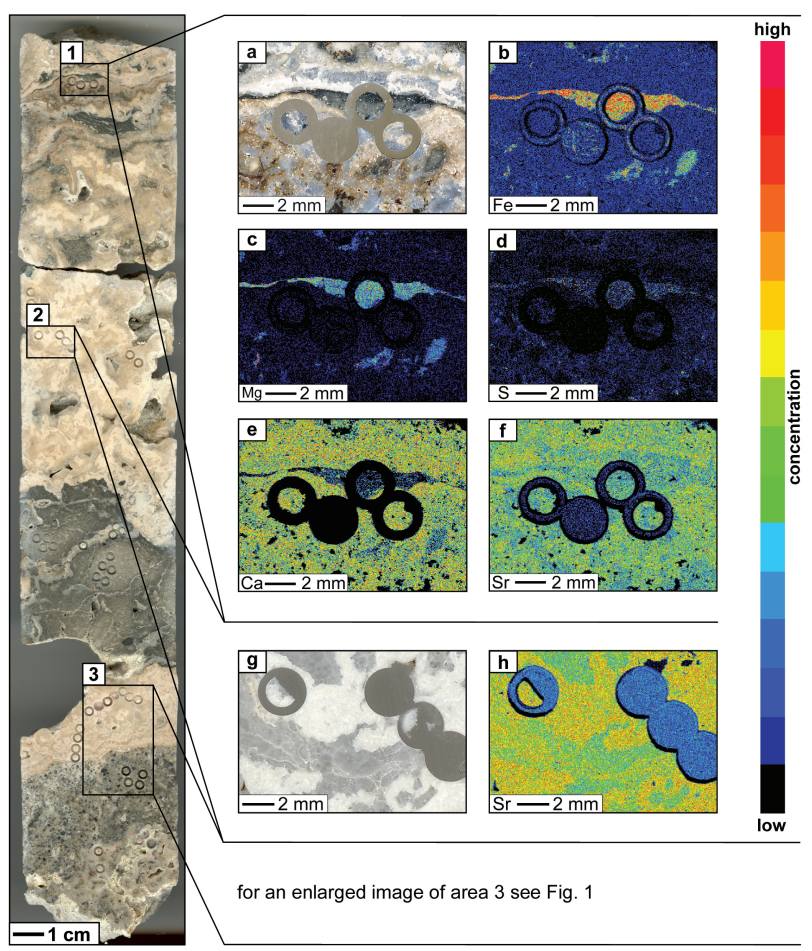

Fig. 3. Cross-section of the sampled drill core with areas 1,2 , and 3 (marked by black frames) analyzed by electron microprobe and/or sampled for miniaturized biomarker analyses. (a) Reflected light image of thin section area 1 showing layer of gray micrite surrounded by lucent aragonite and a pinkish variety of whitish aragonite. (b) Element map showing Fe distribution of area 1. (c) Element map showing $\mathrm{Mg}$ distribution of area 1. (d) Element map showing $\mathrm{S}$ distribution of area 1. (e) Element map showing Ca distribution of area 1. (f) Element map showing $\mathrm{Sr}$ distribution of area 1. (g) Reflected light image of thin section area 2 showing lucent and whitish aragonite. (h) Element map showing Sr distribution of area 2.

bial consortia dominated by ANME- 2 vs. ANME-1. Concentrations of these compounds are highest in the whitish aragonite. Here, the $s n$-2-hydroxyarchaeol/archaeol ratios range from 0.48 to 2.13 (Table 1). On a first view this spread might be interpreted in terms of varying contributions of ANME-1 vs. ANME-2 archaea, respectively, both of which observed in sediments from Hydrate Ridge (Elvert et al., 2005; Knittel et al., 2003). Although sn-2-hydroxyarchaeol has been found in the fossil record (Peckmann and Thiel, 2004; Birgel et al., 2008), a preferential diagenetic degradation, or even conversion to archaeol by dehydroxylation of the phytyl moiety may be anticipated. Therefore, the ratios of $s n$-2-hydroxyarchaeol/archaeol of Hydrate Ridge material must be interpreted with caution when comparing with data from recent microbial consortia. As the studied carbonates are several ten thousand years old, the original abundance of $s n$-2-hydroxyarchaeol may have been considerably higher than presently observed. Taking into account the prominent 
occurrence of crocetane found exclusively in whitish aragonite samples (Table 1), we propose that ANME-2 archaea were directly involved in forming this carbonate type. However, the involvement of ANME-1 archaea in the precipitation of the whitish aragonite cannot be excluded from the present data, as no robust ANME-1 biomarkers such as GDGTs could be analyzed due to the small sample amounts used.

High abundances of DAGEs with non-isoprenoid alkyl moieties have been assigned to the SRB present in the methanotrophic consortia (Pancost et al., 2001) due to their structural similarity to ether lipids of some deeply branching bacteria. Here, we follow this commonly accepted interpretation. However, it should be pointed out that no terminally branched fatty acids that would further support the bacterial origin of DAGEs were detected within the samples. Corresponding findings were reported by Elvert et al. (2005), who observed high abundances of these DAGEs in sections of a Hydrate Ridge sediment core where ANME-1 dominated while the numbers of SRB-cells were markedly low. Consequently, these authors challenged the bacterial origin of DAGEs. Although the exact source organisms in these systems are as yet unclear, the high abundances of DAGEs in the whitish aragonite and the strong correlation with archaeal isoprenoid biomarkers clearly imply an origin from within the consortia involved in AOM.

The stable carbon isotope signature with $\delta^{13} \mathrm{C}$-values as low as $-40.59 \%$ o PDB is well within the range for methanederived carbonates (e.g. Ritger et al., 1987) and corresponds to results from other SE-Knoll carbonates (Teichert et al., 2005). Combined with the high, AOM-specific biomarker content, the stable carbon isotope signature suggests that the whitish aragonite likely originated from bicarbonate produced by AOM in periods of high methane-rich fluid supply.

\subsection{Lucent aragonite}

The traces of lipid biomarkers in the lucent aragonite did not show any specific pattern (Fig. 1). Considering (i) the low sample amounts used, (ii) the low compound concentrations, and (iii) the absence of a characteristic biomarker pattern, contamination from the other carbonate phases during sample preparation is a conceivable source for the lipids observed in the lucent aragonite samples. Thus, it seems unlikely that particular AOM-related (and other) microorganisms are spatially associated with the precipitation of the lucent aragonite, as proposed for the whitish aragonite. Nevertheless, the stable carbon isotope values as low as $-46.98 \%$ o PDB suggest that AOM is still the main bicarbonate source for the lucent aragonite. Taking into account the low biomarker concentrations, we propose that bicarbonate was not produced in situ, but rather was diffusing in from nearby AOM-consortia and thus led to the precipitation of the lucent aragonite.

\subsection{Gray micrite}

In the gray micrite, abundant $\mathrm{Mg}$ reflects a partly $\mathrm{Mg}$-calcitic mineralogy, corresponding to micrites described at another SE-Knoll location (Teichert et al., 2005). Furthermore, the similarity of distributions of $\mathrm{Fe}$ and $\mathrm{S}$ in the gray micrite indicates likely pyrite occurrence in these carbonates (Fig. 3b, d; see also Teichert et al., 2005). The gray micrite contained biomarker compounds from both compound clusters revealed by factor analysis (Fig. 2). The presence of PMI, archaeol, and DAGEs, together with the conspicuous absence of $s n$-2-hydroxyarchaeol and the very low amounts of crocetane, suggests that ANME-1 archaea rather than ANME2 archaea are involved in the formation of the gray micrite. As ANME-1 archaea were found to oxidize methane at lower rates than ANME-2 archaea in laboratory experiments (Nauhaus et al., 2005), this might indicate low background methane supply during the precipitation of the gray micrite. On the other hand, factor analysis suggests that long-chain $n$-alkanes, conventional sterols (sitosterol, cholesterol), and $n$-fatty acids represent water-column-sourced contributions rather than AOM-derived compounds. In this context, it is interesting that the intermediate position of $n$-tricosane between the two compound clusters (Fig. 2) corresponds with a dual, partly AOM-related, origin of this hydrocarbon (Thiel et al., 2001). Perylene, which is thought to originate from both terrestrial and aquatic organic matter during diagenesis (Silliman et al., 2000), is presumably derived from allochthonous sources. The stable carbon isotope signature with values as low as $-45.80 \%$ PDB clearly characterizes the carbonates of the gray micrite as methane-derived. The combined findings are interpreted to reflect incorporation of allochthonous organic and inorganic matter during AOMinduced carbonate precipitation resulting in the formation of the gray micrite. This supports the assumption of Teichert et al. (2005) that the gray micrite formed from cementation of pelagic particles by methane-derived carbonates in periods of episodic cessation of methane seepage.

\section{Conclusions}

Combining miniaturized lipid biomarker analysis, stable carbon isotope analysis, and electron microprobe analysis allowed us to resolve biosignatures of a complex microbialite at the $\mathrm{mm}$-scale and further facilitated the development of a model for the origin of distinct carbonate phases. The results showed a highly localized distribution of lipid biomarkers within the Hydrate Ridge carbonates. More than $90 \%$ of the AOM-related lipid signature was concentrated in only about $20 \%$ of the total carbonate rock volume, specifically in a whitish aragonite phase. The biomarker and inorganic patterns of the whitish aragonite were highly specific and indicated an association with methanotrophic consortia containing mainly ANME-2 archaea and sulfate-reducing bacteria. 
We suggest that the whitish aragonite formed during periodic methane-rich fluid pulses that disrupted the sediment and led to the growth of the respective microorganisms along fluid pathways.

By contrast, low amounts of lipid biomarkers observed in the lucent aragonite indicated that the formation of this precipitate may have lacked the immediate proximity of microorganisms, but rather occurred during intermittent periods of indiffusing AOM derived bicarbonate.

The gray micrite showed both authigenic and allochthonous signals that likely originated from carbonate cementation of allochthonous organic and inorganic matter caused by microbial anaerobic methanotrophy during phases of low background methane supply.

In summary, the results of this study showed that the three main phases of the Hydrate Ridge seep carbonates all originated from AOM-derived bicarbonate. However, the biomarker data indicate that the type of carbonate formed and the microorganisms involved show considerable variation, possibly depending on the availability of methane-rich fluids.

Acknowledgements. We are grateful to Peter Linke and Christine Utecht (IFM-GEOMAR, The Leibniz Institute of Marine Sciences at the University of Kiel), who coordinated the joint project COMET (COntrols on METhane fluxes and their climatic relevance in marine gas hydrate-bearing sediments), and Anton Eisenhauer (IfM-GEOMAR), chief scientist of RV 'Sonne' cruise 165/2, which retrieved the carbonates studied here. We furthermore thank Daniel Birgel (RCOM Bremen), Kai Mangelsdorf (GFZ Potsdam), and Jan Toporski (WITec, Ulm) for reviewing the original manuscript and many constructive comments. We further wish to acknowledge Klaus Simon (University of Göttingen) for an introduction to factor analysis. This study was financially supported by the Deutsche Forschungsgemeinschaft (Grant Th 713/3) and by the German Ministry of Education and Research (BMBF) (Grant 03G0600D, COMET). This is publication No. GEOTECH - 294 of the R\&D-Programme GEOTECHNOLOGIEN.

Edited by: J. Toporski

\section{References}

Birgel, D., Elvert, M., Han, X., and Peckmann, J.: ${ }^{13}$ C-depleted biphytanic diacids as tracers of past anaerobic oxidation of methane, Org. Geochem., 39, 152-156, 2008.

Blumenberg, M., Seifert, R., Reitner, J., Pape, T., and Michaelis, W.: Membrane lipid patterns typify distinct anaerobic methanotrophic consortia, P. Natl. Acad. Sci. USA, 101, 11 111-11 116, 2004.

Boetius, A., Ravenschlag, K., Schubert, C., Rickert, D., Widdel, F., Gieseke, A., Amann, R., Jørgensen, B. B., Witte, U., and Pfannkuche, O.: A marine microbial consortium apparently mediating anaerobic oxidation of methane, Nature, 407, 623-626, 2000 .
Bohrmann, G., Greinert, J., Suess, E., and Torres, M.: Authigenic carbonates from the Cascadia subduction zone and their relation to gas hydrate stability, Geology, 26, 647-650, 1998.

Bohrmann, G., Linke, P., Suess, E., and Pfannkuche, O.: FS SONNE Cruise Report SO143, GEOMAR Rep. 93, 243 pp., 2000.

Cattell, R. B.: The scree test for the number of factors, Multivar. Behav. Res., 1: 245-276, 1966.

Elvert, M., Hopmans, E. C., Treude, T., Boetius, A., and Suess, E.: Spatial variations of methanotrophic consortia at cold methane seeps: implications from a high-resolution molecular and isotopic approach, Geobiology, 3, 195-209, 2005.

Fietzke, J., Liebetrau, V., Eisenhauer, A., and Dullo, Ch.: Determination of uranium isotope ratios by multi-static MIC-ICP-MS: method and implementation for precise $\mathrm{U}$ - and Th-series isotope measurements, J. Anal. Atom. Spectrom., 20, 395-401, 2005.

Greinert, J., Bohrmann, G., and Suess, E.: Gas hydrate-associated carbonates and methane-venting at Hydrate Ridge: classification, distribution, and origin of authigenic lithologies, in: Natural Gas Hydrates: Occurrence, Distribution, and Detection, edited by: Paull, C. K. and Dillon, W. P., American Geophysical Union, Washington, DC, USA, 99-113, 2001.

Hinrichs, K.-U., Hayes, J. M., Sylva, S. P., Brewer, P. G., and DeLong, E. F.: Methane-consuming archaebacteria in marine sediments, Nature, 398, 802-805, 1999.

Hinrichs, K.-U., Summons, R. E., Orphan, V., Sylva, S. P., and Hayes, J. M.: Molecular and isotopic analyses of anaerobic methane-oxidizing communities in marine sediments, Org. Geochem., 31, 1685-1701, 2000.

Kaiser, H. F.: The varimax criterion for analytic rotation in factor analyses, Psychometrika, 23, 187-200, 1958.

Kaiser, H. F.: The application of electronic computers to factor analysis, Educ. Psychol. Meas., 19, 141-151, 1959.

Knittel, K., Boetius, A., Lemke, A., Eilers, H., Lochte, K., Pfannkuche, O., Linke, P., and Amann, R.: Activity, distribution, and diversity of sulfate reducers and other bacteria in sediments above gas hydrate (Cascadia margin, Oregon), Geomicrobiol. J., 20, 269-294, 2003.

Kulm, L. D. and Suess, E.: Relationship between carbonate deposits and fluid venting: Oregon accretionary prism, J. Geophys. Res., 95, 8899-8915, 1990.

Michaelis, W., Seifert, R., Nauhaus, K., Treude, T., Thiel, V., Blumenberg, M., Knittel, K., Gieseke, A., Peterknecht, K., Pape, T., Boetius, A., Amann, R., Jørgensen, B. B., Widdel, F., Peckmann, J., Pimenov, N. V., and Gulin, M. B.: Microbial reefs in the black sea fueled by anaerobic oxidation of methane, Science, 297, 1013-1015, 2002.

Nauhaus, K., Treude, T., Boetius, A., and Krüger, M.: Environmental regulation of the anaerobic oxidation of methane: A comparison of ANME-I and ANME-II communities, Environ. Microbiol., 7, 98-106, 2005.

Orphan, V. J., House, C. H., Hinrichs, K.-U., McKeegan, K. D., and DeLong, E. F.: Multiple archaeal goups mediate methane oxidation in anoxic cold seep sediments, P. Natl. Acad. Sci. USA, 99, 7663-7668, 2002.

Pancost, R. D., Bouloubassi, I., Aloisi, G., Sinninghe Damsté, J. S., and the Medinaut Shipboard Scientific Party: Three series of non-isoprenoid dialkyl glycerol diethers in cold-seep carbonate crusts, Org. Geochem., 32, 695-707, 2001. 
Pape, T., Blumenberg, M., Seifert, R., Gulin, S.B., Egorov, V. N., and Michaelis, W.: Lipid geochemistry of methane-derived Black Sea carbonates, Palaeogeogr. Palaeocl., 227, 31-47, 2005. Peckmann, J., Reimer, A., Luth, U., Luth, C., Hansen, B. T., Heinicke, C., Hoefs, J., and Reitner, J.: Methane-derived carbonates and authigenic pyrite from the northwestern Black Sea, Mar. Geol., 177, 129-150, 2001.

Peckmann, J. and Thiel, V.: Carbon cycling at ancient methaneseeps. Chem. Geol., 205, 433-467, 2004.

Reitner, J., Peckmann, J., Reimer, A., Schumann, G., and Thiel, V.: Methane-derived carbonate build-ups and associated microbial communities at cold seeps on the lower Crimean shelf (Black Sea), Facies, 51, 66-79, 2005.

Ritger, S., Carson, B., and Suess, E.: Methane-derived authigenic carbonates formed by subduction-induced pore-water expulsion along the Oregon/Washington margin. Geol. Soc. Am. Bull., 98, 147-156. 1987.
Silliman, J. E., Meyers, P. A., Ostrom, P. H., Ostrom, N. E., and Eadie, B. J.: Insights into the origin of perylene of sediments from Saanich Inlet, British Columbia, Org. Geochem., 31, 1133$1142,2000$.

Teichert, B. M. A., Bohrmann, G., and Suess, E.: Chemoherms on Hydrate Ridge - Unique microbially-mediated carbonate buildups growing into the water column, Palaeogeogr. Palaeocl., 227, 67-85, 2005.

Thiel, V., Peckmann, J., Schmale, O., Reitner, J., and Michaelis, W.: A new straight-chain hydrocarbon biomarker associated with anaerobic methane cycling, Org. Geochem., 32, 1019-1023, 2001. 